R. Assaloni · R. Da Ros - L. Quagliaro • L. Piconi •

A. Maier · G. Zuodar · E. Motz - A. Ceriello

\title{
Effects of S21403 (mitiglinide) on postprandial generation of oxidative stress and inflammation in type 2 diabetic patients
}

Received: 14 October 2004 / Accepted: 20 March 2005 / Published online: 9 July 2005

(C) Springer-Verlag 2005

\begin{abstract}
Aim/hypothesis: Evidence suggests that postprandial hyperglycaemia may be a cardiovascular risk factor in diabetes. Oxidative stress and inflammation are involved in the pathogenesis of diabetic complications and previous studies have shown increased oxidative stress and inflammation in the postprandial phase in diabetic patients. The aim of the present study was to evaluate whether controlling postprandial hyperglycaemia with S21403 (mitiglinide) is accompanied by a reduced generation of oxidative stress and inflammation. Subjects and methods: Forty type 2 diabetic patients participated in the study. Two different breakfast-tests were performed in each patient, with placebo or S21403. Plasma nitrotyrosine, plasma malondialdehyde (MDA), oxidised LDL (oxLDL), plasma total radical-trapping antioxidant parameter (TRAP), IL-6, IL-18, TNF- $\alpha$, plasma glucose and insulin were measured. Results: After the administration of S21403, $40 \mathrm{mg}$, a rapid stimulation of insulin secretion was observed, accompanied by a reduction of postprandial hyperglycaemia. With S21403, a significant decrease of either nitrotyrosine, MDA and oxLDL levels, and a preservation of plasma TRAP compared with placebo was found. Significant decreases of IL-6, IL-18 and
\end{abstract}

R. Assaloni · R. Da Ros · A. Maier · G. Zuodar ·

E. Motz · A. Ceriello

Department of Pathology and Medicine,

Experimental and Clinical,

University of Udine,

Udine, Italy

L. Quagliaro · L. Piconi

Morpurgo-Hofman Research Laboratory on Ageing,

Udine, Italy

A. Ceriello $(\bowtie)$

Internal Medicine,

University of Udine,

P. le S. Maria della Misericordia,

33100 Udine, Italy

e-mail: ceriello@uniud.it

Tel.: +39-0432-559813

Fax: +39-0432-42097
TNF- $\alpha$ were also observed with S21403 compared with placebo. Conclusions/interpretation: This study shows that controlling postprandial hyperglycaemia with S21403 significantly improves the cluster of oxidative stress and inflammation markers that are increased in the postprandial state in diabetic patients.

Keywords Inflammation - Mitiglinide - Oxidative stress · Postprandial hyperglycaemia

Abbreviations CVD: Cardiovascular disease - MDA: Malondialdehyde - oxLDL: Oxidised LDL - TRAP: Total radical-trapping antioxidant parameter

\section{Introduction}

Patients with diabetes have an increased risk of cardiovascular morbidity and mortality [1]. In recent years much attention has been paid to the causal relationship between the postprandial state and atherogenesis [2, 3], even in diabetes mellitus [4,5], and it has been suggested that postprandial hyperglycaemia may be an independent risk factor for cardiovascular disease (CVD) $[6,7]$.

There is growing evidence that oxidative stress, i.e. the imbalance between free-radical production and antioxidant defence [8,9], and inflammation [10] are involved in the pathogenesis of CVD in diabetes mellitus. Postprandial generation of both oxidative stress [11-13] and inflammation [13-15] has been demonstrated in type 2 diabetic patients. However, it is still unclear whether this phenomenon can be controlled in clinical practice by modulating postprandial hyperglycaemia.

In this study, the effect of an oral compound, S21403 (mitiglinide), a rapid and short-acting insulin secretagogue that reduces postprandial hyperglycaemia [16], on postprandial generation of oxidative stress and inflammation was studied.

Plasma nitrotyrosine, malondialdehyde (MDA), oxidised LDL (oxLDL) and total radical-trapping antioxidant parameter (TRAP) were measured as markers of oxidative stress; 
IL-6, IL-18 and TNF- $\alpha$ were evaluated as inflammatory markers.

\section{Subjects and methods}

\section{Subjects}

Men and women with type 2 diabetes according to WHO criteria, between 35 and 72 years of age, with a BMI between 22 and $35 \mathrm{~kg} / \mathrm{m}^{2}$ and currently being treated by diet alone and having an $\mathrm{HbA}_{1} \mathrm{c}$ above $6.5 \%$, or being treated by hypoglycaemic agents except insulin sensitisers and having an $\mathrm{HbA}_{1} \mathrm{c}$ between 6 and $10 \%$, were eligible to participate in the study. The following treatments were allowed if prescribed at stable dosage during the whole study: antihypertensive drugs including ACE inhibitors, lipid-lowering drugs and oestrogen therapy as in contraceptive pills or in hormone replacement therapy for postmenopausal women.

Inclusion criteria also included a fasting capillary blood glucose level between 7 and $14 \mathrm{mmol} / \mathrm{l}$ measured just before the first breakfast-test.

Major exclusion criteria were: type 1 diabetes or insulin treatment; and in type 2 diabetic patients treatment with an insulin sensitiser or with more than one antidiabetic drug, or with drugs that could interfere with glucose metabolism, or with antioxidant supplementation. Other chronic diseases known to affect glucose control were also exclusion criteria, as were uncontrolled macroangiopathy, evidence of hepatic or renal disease (transaminases more than three times the upper normal value, or a plasma creatinine level above $140 \mu \mathrm{mol} / \mathrm{l}$, macroalbuminuria $>300 \mathrm{mg} / 24 \mathrm{~h}$ ), uncontrolled dyslipidaemia (triglycerides above $2.5 \mathrm{mmol} / \mathrm{l}$ ), pregnancy and breastfeeding.

All patients gave their written informed consent to participate in the study and the study centre received local ethics committee approval. The study was conducted in accordance with the ethical principles stated in the Declaration of Helsinki, 1964, amended in Edinburgh in 2000.

\section{Study plan}

This was a phase II, double-blind, placebo-controlled, cross-over study. It was performed in 40 diabetic outpatients being monitored in the Department of Internal Medicine, University of Udine, Italy. The demographic data and other baseline characteristics of the patients are described in the Table 1. In the randomised population, 11 patients $(27.5 \%)$ had a history of hypertension, and five $(12.5 \%)$ had a history of hyperlipidaemia.

After a 7-day run-in placebo period, if eligible, each patient was randomly assigned to undergo two standardised breakfast-tests performed 2 days apart. The two sequences of treatment were randomly assigned at the first breakfast-test.

The 2-h breakfast-tests were performed at the hospital under the same conditions.
Table 1 Baseline characteristics of the patients

\begin{tabular}{lc}
\hline Age (years) & $59.1 \pm 8.0$ \\
Sex & $39 \mathrm{M} / 9 \mathrm{~F}$ \\
BMI $\left(\mathrm{kg} / \mathrm{m}^{2}\right)$ & $27.5 \pm 3.4$ \\
Weight $(\mathrm{kg})$ & $81.2 \pm 13.9$ \\
Duration of diabetes (months) & $57.1 \pm 42.9$ \\
$\mathrm{HbA}_{1} \mathrm{c}(\%)$ & $6.86 \pm 0.50$ \\
Fasting blood glucose (mmol/l) & $8.67 \pm 1.58$ \\
Systolic BP $(\mathrm{mmHg})$ & $146.4 \pm 15.2$ \\
Diastolic BP $(\mathrm{mmHg})$ & $88.1 \pm 6.2$ \\
Total cholesterol $(\mathrm{mmol} / \mathrm{l})$ & $5.94 \pm 1.40$ \\
Triglycerides $(\mathrm{mmol} / \mathrm{l})$ & $1.62 \pm 0.61$ \\
HDL (mmol/l) & $1.40 \pm 0.38$ \\
LDL (mmol/l) & $3.67 \pm 1.20$
\end{tabular}

Data are means \pm SD

During the 7-day run-in period, as well as during the 2day period between the two breakfast-tests, placebo was given three times a day immediately before meals.

The total duration of the study for each patient was 11 days.

The patients attended the Diabetes Unit at 07.00 hours after a 10-h fast (from 21.00 hours on the day before each breakfast-test). The fasting capillary blood glucose level was measured (with a glucose meter) immediately before the breakfast-tests.

The second breakfast-test was performed 2 days after if glycaemic control was relatively stable, i.e. if the difference in the fasting capillary blood glucose level between the two-breakfast-tests was $\leq 3 \mathrm{mmol} / \mathrm{l}$.

If not, the patient had to come back within 10 days after and the investigator checked if it was possible to perform the breakfast-test on this other day.

A standardised breakfast that was designed to have negligible antioxidant content $(600 \mathrm{kcal}, 50 \%$ carbohydrate, $30 \%$ fat and $20 \%$ protein without significant amounts of vitamin $\mathrm{C}, \alpha$-tocopherol, carotenoids and flavonoids), was given at 08.00 hours. The composition of the breakfast was as follows: whole milk $125 \mathrm{ml}$, yoghurt $125 \mathrm{~g}$, bread $90 \mathrm{~g}$, butter $10 \mathrm{~g}$ and ham $60 \mathrm{~g}$. The patient took the study-drug tablet immediately after the first blood sample and before the breakfast. The breakfast had to be eaten within $20 \mathrm{~min}$. Time zero corresponds to the administration of the study drug. The patient was at rest, in a seated position, throughout the test. Plasma nitrotyrosine (main efficacy criterion), MDA, TRAP, plasma glucose, plasma insulin, oxLDL, IL-6, IL-18 and TNF- $\alpha$ were measured at 0 and $120 \mathrm{~min}$.

\section{Determination of sample size}

For this exploratory study, the number of patients was estimated from the results of limited data obtained on the main efficacy criterion nitrotyrosine (Ceriello et al. [17 and unpublished data]). 
Sample size was estimated on the change between time 0 and $120 \mathrm{~min}$ of nitrotyrosine during the meal-test for a difference of $0.1 \mu \mathrm{mol} / 1$ between placebo and S21403 using the two-sided Student's $t$-test for paired samples at $5 \%$ type I error.

For a $0.12 \mu \mathrm{mol} / 1 \mathrm{SD}, 35$ patients were necessary to detect at least $0.1 \mu \mathrm{mol} / 1$ difference between treatments with $95 \%$ power and at least 0.1 correlation coefficient $\rho$ between measurements.

Taking into account the uncertainties of the estimation, it was decided to randomise 40 patients.

\section{Assays}

All the parameters were analysed in the laboratory of the centre.

Nitrotyrosine plasma concentration was assayed by ELISA [17] and expressed in $\mu \mathrm{mol} / \mathrm{L}$.

MDA was evaluated according to [18] and corrected to triglyceride and cholesterol concentration and expressed as $\mu \mathrm{mol} / \mathrm{L}$.

TRAP was evaluated as previously described [11]. Values are expressed as $\mu \mathrm{mol} / \mathrm{L}$.

We assessed oxLDL by the Mercodia Oxidized LDL ELISA (Mercodia AB, Uppsala, Sweden), according to the method described by Holvoet et al. [19], and expressed it in $\mathrm{U} / \mathrm{L}$.

IL-6, IL-18 and TNF- $\alpha$ plasma concentrations were assayed by commercially available ELISA kits (Bender MedSystems Diagnostics, Vienna, Austria), and expressed in $\mathrm{pg} / \mathrm{ml}$.

Insulin (Immuno Lite, Diagnostic Products Corporation, Los Angeles, CA, USA) was expressed as pmol/L.

\section{Statistical analysis}

The main efficacy criterion was the plasma nitrotyrosine level.
The secondary efficacy criteria were plasma levels of MDA, TRAP and oxLDL as oxidative stress markers and plasma concentrations of IL- 6 , IL-18 and TNF- $\alpha$ as inflammatory markers.

All these criteria were studied as changes from 0 to 120 $\min$.

The main statistical analysis was performed with a type I error at 5\% in order to evaluate the acute effect of S21403 $40 \mathrm{mg}$ compared with placebo on nitrotyrosine changes between time 0 and $120 \mathrm{~min}$. All statistical analyses were performed using a general linear model adapted to the cross-over design [20], with adjustment on period factor and taking into account the patient as a random factor. The S21403 treatment effect as compared with placebo was estimated and tested using the difference between adjusted treatment means (on period). Statistical significance was defined as $p<0.05$.

\section{Results}

In the randomised population, 11 patients $(27.5 \%)$ had a history of hypertension: six patients $(30 \%)$ in the sequence placebo-S21403 and five patients $(25 \%)$ in the sequence S21403-placebo. Five patients $(12.5 \%)$ had a history of hyperlipidaemia, three patients $(15 \%)$ in sequence placeboS21403 and two patients (10\%) in sequence S21403placebo.

Plasma glucose and insulin

At baseline, plasma insulin and plasma glucose levels were similar in the treatment and placebo groups (Table 2). After a single administration of S21403 $40 \mathrm{mg}$ a rapid stimulation of insulin secretion was observed compared with placebo. This insulin release induced a significant reduction of postprandial hyperglycaemia with S21403 compared with placebo at $120 \mathrm{~min}$ (Table 2).

Table 2 Effects of the treatments

\begin{tabular}{|c|c|c|c|c|c|c|}
\hline & \multicolumn{2}{|c|}{$\begin{array}{l}\text { Baseline value (T0) } \\
(\text { mean } \pm \mathrm{SD})\end{array}$} & \multicolumn{2}{|c|}{ Last value (T120) $($ mean \pm SD) } & \multicolumn{2}{|c|}{ Difference at T120 of adjusted mean of treatment } \\
\hline & S21403 & Placebo & S21403 & Placebo & $\mathrm{E} \pm \mathrm{SE}^{\mathrm{a}}(95 \% \mathrm{CI})$ & $p$-value ${ }^{\mathrm{b}}$ \\
\hline Plasma glucose (mmol/1) & $8.55 \pm 1.89$ & $8.43 \pm 1.86$ & $9.26 \pm 3.56$ & $12.3 \pm 3.37$ & $-3.12 \pm 0.30(-3.72$ to -2.51$)$ & $<0.001$ \\
\hline Insulin (pmol/1) & $65.90 \pm 44.40$ & $68.50 \pm 74.80$ & $565.6 \pm 342.4$ & $389.2 \pm 312.8$ & $179.05 \pm 44(90.06$ to 268.04$)$ & $<0.001$ \\
\hline Nitrotyrosine $(\mu \mathrm{mol} / \mathrm{l})$ & $0.399 \pm 0.185$ & $0.404 \pm 0.180$ & $0.445 \pm 0.211$ & $0.544 \pm 0.193$ & $-0.094 \pm 0.014(-0.122$ to -0.067$)$ & $<0.001$ \\
\hline $\operatorname{MDA}(\mu \mathrm{mol} / \mathrm{l})$ & $51.22 \pm 0.30$ & $1.08 \pm 0.35$ & $1.44 \pm 0.41$ & $1.46 \pm 0.42$ & $-0.16 \pm 0.07(-0.31$ to -0.01$)$ & $<0.05$ \\
\hline TRAP $(\mu \mathrm{mol} / 1)$ & $210.7 \pm 13.48$ & $211.0 \pm 13.30$ & $198.2 \pm 17.17$ & $194.2 \pm 14.06$ & $4.36 \pm 1.83(0.65$ to 8.07$)$ & $<0.05$ \\
\hline oxLDL (U/1) & $81.89 \pm 22.17$ & $79.60 \pm 15.86$ & $89.32 \pm 20.63$ & $95.63 \pm 18.55$ & $-8.597 \pm 1.568(-11.772$ to -5.423$)$ & $<0.001$ \\
\hline IL-6 (pg/ml) & $0.632 \pm 0.347$ & $0.619 \pm 0.408$ & $0.671 \pm 0.383$ & $0.800 \pm 0.364$ & $-0.142 \pm 0.036(-0.215$ to -0.069$)$ & $<0.001$ \\
\hline IL-18 (pg/ml) & $146.2 \pm 125.5$ & $136.3 \pm 93.81$ & $222.2 \pm 99.28$ & $341.5 \pm 139.1$ & $-129.20 \pm 30.34(-190.61$ to -67.79$)$ & $<0.001$ \\
\hline TNF- $\alpha(\mathrm{pg} / \mathrm{ml})$ & $6.98 \pm 0.91$ & $6.98 \pm 0.89$ & $7.36 \pm 0.98$ & $8.52 \pm 0.99$ & $-1.188 \pm 0.247(-1.681$ to -0.695$)$ & $<0.001$ \\
\hline
\end{tabular}

$M D A$ Malondialdehyde, $o x L D L$ oxidised LDL, T0 time at $0 \mathrm{~min}, T 120$ time at $120 \mathrm{~min}, T R A P$ total radical-trapping antioxidant parameter ${ }^{a}$ Estimate \pm SE of the difference S21403 minus placebo: difference between adjusted treatment means

${ }^{\mathrm{b}}$ Two-sided Student's $t$-test on adjusted treatment means 


\section{Primary efficacy criterion}

The primary objective was to evaluate the acute effect of S21403 $40 \mathrm{mg}$ compared with placebo on the increaseinduced by hyperglycaemic spikes during meals - in plasma nitrotyrosine between 0 and $120 \mathrm{~min}$.

At baseline, the plasma nitrotyrosine level was similar in both treatment and placebo groups (Table 2).

At $120 \mathrm{~min}$, the increase in the plasma nitrotyrosine level was significantly smaller in the S21403 group than in the placebo group (Table 2).

\section{Secondary efficacy criteria}

Oxidative stress The acute effect of S21403 $40 \mathrm{mg}$ compared with placebo on oxidative stress induced by hyperglycaemic spikes during meals was also evaluated through the analysis of the plasma concentration changes over time of the following secondary criteria: MDA, TRAP and oxLDL.

The plasma MDA level was quite high in the S21403 group (Table 2). At $120 \mathrm{~min}$, the increase in plasma MDA was significantly smaller in the S21403 group than in the placebo group (Table 2). Given the observed imbalance between the baseline measures of the two treatments at the breakfast-tests (time 0), an analysis adjusted on the baseline value was performed. The results were quite consistent with the previous analysis $(-0.132 ; 95 \%$ CI -0.276 to $0.013, p=0.07$ ).

The basal plasma levels of either TRAP and oxLDL were similar in both groups of treatments as shown in Table 2. The TRAP decrease over time was significantly smaller with S21403 than with placebo, as described in Table 2. At $120 \mathrm{~min}$, the plasma oxLDL level was significantly decreased by S21403 vs placebo (Table 2).

Inflammation The effect of S21403 on inflammation compared with placebo was assessed by analyses of plasma concentrations of IL-6, IL-18 and TNF- $\alpha$, systemic markers of inflammation. Plasma levels of IL-6, IL-18 and TNF- $\alpha$ were similar in each treatment group at baseline (Table 2). During the breakfast-test a significant decrease of plasma levels of IL-6, IL-18 and TNF- $\alpha$ was observed over time with S21403 compared with placebo (Table 2).

\section{Discussion}

There is widespread agreement that diabetes increases the risk of CVD [1]. Oxidative stress and inflammation are widely recognised as important pathogenic factors of atherosclerosis, even in diabetes mellitus [4].

Postprandial hyperglycaemia has recently been proposed as an independent risk factor for CVD [6, 7]. However, the effect of the postprandial state, particularly postprandial hyperglycaemia, on CVD is still a matter of debate $[21,22]$; studies show that postprandial hyperglycaemia is accompanied by an increase of both oxidative stress and inflammatory markers [11-15]. This evidence is supported by findings showing an increase in vivo, during postprandial hyperglycaemia, of both protein kinase $\mathrm{C}$ and nuclear factor kappa B, two factors which regulate the generation of oxidative stress and inflammation [23, 24].

Our study confirms that a meal in diabetic patients is followed by an increase of oxidative stress and inflammation. However, for the first time, we show that modulating postprandial hyperglycaemia in type 2 diabetic patients by means of an oral hypoglycaemic agent, S21403, that specifically targets postprandial hyperglycaemia, can reduce the generation of oxidative stress and inflammation in the postprandial state.

We did not perform studies in normal healthy control subjects, therefore our study did not find out how much oxidative stress and inflammation are produced in this category of subjects, nor whether S21403 normalises them. However, the possibility that postprandial hyperglycaemia increases oxidative stress and inflammation in healthy subjects has previously been reported $[12,13]$. Furthermore, evidence showing that modulation of postprandial hyperglycaemia by diet or an insulin analogue in type 2 diabetes [25-27], and by pramlintide [28] in type 1 diabetes, is accompanied by a significant decrease of oxidative stress, while nuclear factor kappa B activation is decreased when controlling postprandial hyperglycaemia by acarbose [24], convincingly suggests that the effect of S21403 on postprandial oxidative stress and inflammation is related to its ability to reduce postprandial hyperglycaemia.

Some of the markers evaluated deserve particular attention. Nitrotyrosine is a suitable marker of peroxynitrite and nitrosative stress generation [29] and an increased nitrotyrosine plasma level has been found in the plasma of diabetic patients $[17,30]$. Interestingly, nitrotyrosine has recently been shown to be an independent risk factor for CVD [30]. Consistently, oxLDL as well as inflammatory cytokines are well recognised as being involved in atherogenesis [31, 32].

Therefore, emerging evidence suggesting that the modulation of postprandial hyperglycaemia makes it possible to reduce these factors, which are very probably involved in the pathogenesis of CVD, seems to be of clinical interest and relevance. This relevance, moreover, seems to be reinforced by several recent clinical trials. The STOPNIDDM trial has presented data indicating that treatment of subjects with IGT with the $\alpha$-glucosidase inhibitor acarbose, a compound which specifically reduces postprandial hyperglycaemia, is associated not only with a $36 \%$ reduction in the risk of progression to diabetes [33], but also with a $34 \%$ risk reduction in the development of new cases of hypertension and a $49 \%$ risk reduction in cardiovascular events [34]. In addition, in a subgroup of patients the carotid intima-media thickness was measured before randomisation and at the end of the study [35]. Acarbose treatment was associated with a significant decrease in the progression of intima-media thickness, an accepted marker of atherosclerosis [35]. Furthermore, in a recent meta-analysis of type 2 diabetic patients, acarbose 
treatment was associated with a significant reduction in cardiovascular events, even after adjusting for other risk factors [36]. Finally, very recently, the effects of two insulin secretagogues, repaglinide and glyburide, which are known to have different efficacy on postprandial hyperglycaemia, on carotid intima-media thickness and markers of systemic vascular inflammation in type 2 diabetic patients, were evaluated [37]. After 12 months, the postprandial glucose peak was $8.2 \pm 1.5 \mathrm{mmol} / 1$ in the repaglinide group and $9.9 \pm 1.7 \mathrm{mmol} / \mathrm{l}$ in the glyburide group $(p<0.01) . \mathrm{HbA}_{1} \mathrm{c}$ showed a similar decrease in both groups $(-0.9 \%)$. Carotid intima-media thickness regression, defined as a decrease of $>0.020 \mathrm{~mm}$, was observed in $52 \%$ of diabetic subjects receiving repaglinide and in $18 \%$ of those receiving glyburide $(p<0.01)$. The reduction in carotid intima-media thickness was associated with changes in postprandial but not fasting hyperglycaemia [37]. Therefore evidence is emerging to suggest that treating postprandial hyperglycaemia may positively affect the development of the CVD.

This study only examined the effect of an acute administration of S21403, therefore no conclusion on the longterm effect of the treatment can be drawn at the moment. However, it seems reasonable that reducing postprandial oxidative stress and inflammation may result in a decrease of CVD.

In conclusion, this study shows that controlling postprandial hyperglycaemia with the specific agent S21403 significantly improves the cluster of oxidative stress and inflammation markers which are significantly increased in the postprandial state in diabetic patients. These data suggest that controlling postprandial hyperglycaemia may significantly contribute to the prevention of CVD in diabetes.

\section{Duality of interest}

This protocol was proposed and carried out by the investigators; the costs of running the study were supported by a grant from Institut de Recherches Servier, Paris, France. No further conflict of interest is declared.

\section{References}

1. Garcia MJ, McNamara PM, Gordon T, Kannel WB (1974) Morbidity and mortality in diabetics in the Framingham population: sixteen-year follow up study. Diabetes 23:105-111

2. Zilversmit DB (1979) Atherogenesis a post-prandial phenomenon. Circulation 60:473-485

3. Ebenbichler CF, Kirchmair R, Egger C, Patsch JR (1995) Postprandial state and atherosclerosis. Curr Opin Lipidol 6:286-290

4. Lefebvre PJ, Scheen AJ (1998) The postprandial state and risk of cardiovascular disease. Diabet Med 15(Suppl 4):S63-S68

5. Ceriello A (2000) The post-prandial state and cardiovascular disease: relevance to diabetes mellitus. Diabetes/Metab Res Rev 16:125-132

6. Bonora E, Muggeo M (2001) Postprandial blood glucose as a risk factor for cardiovascular disease in type II diabetes: the epidemiological evidence. Diabetologia 44:2107-2114
7. Ceriello A, Hanefeld M, Leiter L et al (2004) Postprandial glucose regulation and diabetic complications. Arch Intern Med 164:2090-2095

8. Ceriello A (2003) New insights on oxidative stress and diabetic complications may lead to a 'causal' antioxidant therapy. Diabetes Care 26:1589-1596

9. Brownlee M (2001) Biochemistry and molecular cell biology of diabetic complications. Nature 414:813-820

10. Plutzky J (2004) Inflammation in atherosclerosis and diabetes mellitus. Rev Endocr Metab Disord 5:255-259

11. Ceriello A, Bortolotti N, Motz E et al (1998) Meal-generated oxidative stress in type 2 diabetic patients. Diabetes Care 21:1529-1533

12. Ceriello A, Taboga C, Tonutti L et al (2002) Evidence for an independent and cumulative effect of postprandial hypertriglyceridemia and hyperglycemia on endothelial dysfunction and oxidative stress generation: effects of short- and long-term simvastatin treatment. Circulation 106:1211-1218

13. Ceriello A, Quagliaro L, Piconi L et al (2004) Effect of postprandial hypertriglyceridemia and hyperglycemia on circulating adhesion molecules and oxidative stress generation and the possible role of simvastatin treatment. Diabetes 53:701-710

14. Nappo F, Esposito K, Cioffi M et al (2002) Postprandial endothelial activation in healthy subjects and in type 2 diabetic patients: role of fat and carbohydrate meals. J Am Coll Cardiol 39:1145-1150

15. Esposito K, Nappo F, Marfella R et al (2002) Inflammatory cytokine concentrations are acutely increased by hyperglycemia in humans: role of oxidative stress. Circulation 106:2067-2072

16. Sunaga Y, Gonoi T, Shibasaki T et al (2001) The effects of mitiglinide (KAD-1229), a new anti-diabetic drug, on ATPsensitive $\mathrm{K}^{+}$channels and insulin secretion: comparison with the sulfonylureas and nateglinide. Eur J Pharmacol 431:119125

17. Ceriello A, Mercuri F, Quagliaro L et al (2001) Detection of nitrotyrosine in the diabetic plasma: evidence of oxidative stress. Diabetologia 44:834-838

18. Jentzsch AM, Bachmann H, Furst P, Biesalski HK (1996) Improved analysis of malondialdehyde in human body fluids. Free Radic Biol Med 20:251-256

19. Holvoet P, Vanhaecke J, Janssens S et al (1998) Oxidized LDL and malondialdehyde-modified LDL in patients with acute coronary syndromes and stable coronary artery disease. Circulation 98:1487-1494

20. Senn S (1993) Cross-over trials in clinical research, 1st edn. Wiley, Chichester

21. Buse JB (2003) Should postprandial glucose be routinely measured and treated to a particular target? No! Diabetes Care 26:1615-1618

22. Heine RJ, Dekker JM (2002) Beyond postprandial hyperglycaemia: metabolic factors associated with cardiovascular disease. Diabetologia 45:461-475

23. Assert R, Scherk G, Bumbure A, Pirags V, Schatz H, Pfeiffer AF (2001) Regulation of protein kinase $C$ by short term hyperglycaemia in human platelets in vivo and in vitro. Diabetologia 44:188-195

24. Rudofsky G Jr, Reismann P, Schiekofer S et al (2004) Reduction of postprandial hyperglycemia in patients with type 2 diabetes reduces NF-kappaB activation in PBMCs. Horm Metab Res 36:630-638

25. Ceriello A, Bortolotti N, Motz E et al (1999) Meal-induced oxidative stress and low-density lipoprotein oxidation in diabetes: the possible role of hyperglycemia. Metabolism 48:15031508

26. Ceriello A, Quagliaro L, Catone B et al (2002) Role of hyperglycemia in nitrotyrosine postprandial generation. Diabetes Care 25:1439-1443

27. Beisswenger PJ, Howell SK, O'Dell RM, Wood ME, Touchette AD, Szwergold BS (2001) Alpha-dicarbonyls increase in the postprandial period and reflect the degree of hyperglycemia. Diabetes Care 24:726-732 
28. Ceriello A, Piconi L, Quagliaro L et al (2005) Effects of pramlintide on postprandial glucose excursions and measures of oxidative stress in type 1 diabetes. Diabetes Care 28:632-637

29. Ischiropoulos H (1998) Biological tyrosine nitration: a pathophysiological function of nitric oxide and reactive oxygen species. Arch Biochem Biophys 356:1-11

30. Shishehbor MH, Aviles RJ, Brennan ML et al (2003) Association of nitrotyrosine levels with cardiovascular disease and modulation by statin therapy. JAMA 289:1675-1680

31. Napoli C (2003) Oxidation of LDL, atherogenesis, and apoptosis. Ann NY Acad Sci 1010:698-709

32. Boisvert WA (2004) Modulation of atherogenesis by chemokines. Trends Cardiovasc Med 14:161-165

33. Chiasson JL, Josse RG, Gomis R et al STOP-NIDDM Trial Research Group (2002) Acarbose for prevention of type 2 diabetes mellitus: the STOP-NIDDM randomised trial. Lancet 359:2072-2077
34. Chiasson JL, Josse RG, Gomis R et al STOP-NIDDM Trial Research Group (2003) Acarbose treatment and the risk of cardiovascular disease and hypertension in patients with impaired glucose tolerance: the STOP-NIDDM trial. JAMA 290:486494

35. Hanefeld M, Chiasson JL, Koehler C et al (2004) Acarbose slows progression of intima-media thickness of the carotid arteries in subjects with impaired glucose tolerance. Stroke 35:1073-1078

36. Hanefeld M, Cagatay M, Petrowitsch T et al (2004) Acarbose reduces the risk for myocardial infarction in type 2 diabetic patients: meta-analysis of seven long-term studies. Eur Heart J 25:10-16

37. Esposito K, Giugliano D, Nappo F, Marfella R (2004) Regression of carotid atherosclerosis by control of postprandial hyperglycemia in type 2 diabetes mellitus. Circulation 110:214-219 